\title{
Immunological Reviews
}

Gerritje J. W. van der Windt

Erika L. Pearce
Metabolic switching and fuel choice during T-cell differentiation and memory development
Authors' addresses

Gerritje J. W. van der Windt ${ }^{1}$, Erika L. Pearce ${ }^{1}$

${ }^{1}$ Department of Pathology \& Immunology, Washington

University School of Medicine, St. Louis, MO, USA.

Correspondence to:

Erika L. Pearce

Department of Pathology \& Immunology

Washington University School of Medicine

660 S. Euclid Avenue, Campus Box 8118

St. Louis, MO 63110-1093, USA

Tel.: +13142862509

Fax: +1 3143629108

e-mail: erikapearce@path.wustl.edu

Acknowledgments

We would like to thank Edward Pearce, Bart Everts, and David O'Sullivan for critical reading of the manuscript. Erika Pearce's research is supported by grants from the National Institutes of Health and the Emerald Foundation. Gerritje van der Windt is supported by a fellowship from the Netherlands Organisation for Scientific Research. The authors have no conflicts of interest to declare.

This article is part of a series of reviews covering Metabolism and Autophagy in the Immune System appearing in Volume 249 of Immunological Reviews.
Immunological Reviews 2012

Vol. 249: 27-42

Printed in Singapore. All rights reserved

(C) 2012 John Wiley \& Sons A/S

Immunological Reviews

0105-2896
Summary: Clearance or control of pathogens or tumors usually requires T-cell-mediated immunity. As such, understanding the mechanisms that govern the function, maintenance, and persistence of $\mathrm{T}$ cells will likely lead to new treatments for controlling disease. During an immune response, T-cell development is marked by striking changes in metabolism. There is a growing appreciation that these metabolic changes underlie the capacity of $\mathrm{T}$ cells to perform particular functions, and this has led to a recent focus on the idea that the manipulation of cellular metabolism can be used to shape adaptive immune responses. Although interest in this area has grown in the last few years, a full understanding of the metabolic control of T-cell functions, particularly during an immune response in vivo, is still lacking. In this review, we first provide a basic overview of metabolism in $\mathrm{T}$ cells, and then we focus on recent studies providing new or updated insights into the regulation of metabolic pathways and how they underpin T-cell differentiation and memory T-cell development.

Keywords: T cell, metabolism, immune response

\section{Conventional view of T-cell metabolism}

$\mathrm{T}$ cells develop in the thymus and then enter the periphery, where their role is to protect the body from invading pathogens and cancers. Circulating naive $\mathrm{T}$ cells are quiescent, but upon T-cell receptor (TCR)-mediated recognition of antigen and the receipt of costimulatory signals, these cells become activated, undergo extensive proliferation, and acquire effector functions, such as the ability to produce cytokines and cytolytic molecules. The differences in functional and phenotypic characteristics of quiescent $\mathrm{T}$ cells and activated $\mathrm{T}$ cells are supported by distinct metabolic requirements. Specifically, quiescent $\mathrm{T}$ cells (i.e. naive or memory $\mathrm{T}$ cells) have a catabolic metabolism where nutrients are broken down to fuel cell survival. In contrast, activated $\mathrm{T}$ cells adopt an anabolic metabolism, where nutrients will also be used to construct the molecular building blocks that are incorporated into cellular biomass to support 
proliferation (1-3). The balance of catabolic and anabolic pathways in a cell determines how much adenosine triphosphate (ATP) is generated versus consumed, the availability of biosynthetic precursors, and the redox status of the cell.

Upon activation, $\mathrm{T}$ cells increase in size and undergo a metabolic transition from oxidative phosphorylation (OXPHOS) to glycolysis (4-6) (Fig. 1). Signals from growth factor cytokines like interleukin-2 (IL-2) and the ligation of costimulatory CD28 promote this switch to glycolysis by inducing the phosphoinositol 3-kinase (PI3K)-dependent activation of AKT $(7,8)$. Mamalian target of rapamycin (mTOR) is a key regulator of translation (9) and cell size (10) that stimulates glycolysis and cellular metabolism (11) by increasing glycolytic enzyme activity and enhancing the expression of nutrient transporters. Active AKT promotes the mTOR pathway, thereby enabling increased utilization of glucose and amino acids (2, 12-16). Activated T cells aerobically ferment glucose into lactate, a process that occurs despite the presence of sufficient oxygen to support mitochondrial OXPHOS $(5,6)$ (Fig. 1). This phenomenon is referred to as the Warburg effect, after Otto Warburg who in the 1920s first described this process in cancer cells (17). The current view of metabolism in activated $\mathrm{T}$ cells is one where the induction and maintenance of Warburg metabolism, in addition to glutamine uptake and utilization, is essential for activation, proliferation, and the expression of effector functions (5, 7, 18-21) (Fig. 2).

\section{Glucose and proliferating $\top$ cells}

Glucose is an essential nutrient for T cells, and its uptake is regulated by glucose transporter expression (22). TCR stimulation leads to trafficking of the glucose transporter Glut 1 from intracellular vesicles to the cell surface (8), while signals via CD28 and growth factor cytokines further increase its expression and cell surface localization $(1,5,7)$. Naive T cells isolated from Glut1 overexpressing mice are larger, and these mice have increased the numbers of $\mathrm{CD} 44^{\text {hi }} \mathrm{T}$ cells, suggesting that the earliest steps in T-cell activation, the increase in cell size and activation marker expression, are dependent on glucose utilization (18). It has also been shown that in the absence of glucose, T-cell survival and proliferation is impaired, even in the presence of an alternative carbon source such as glutamine $(18,23)$. In addition, T-cell cytokine production is also thought to be dependent on glucose. For example, glucose deprivation has been shown to strongly inhibit IFN- $\gamma$ gene expression $(18,24)$,

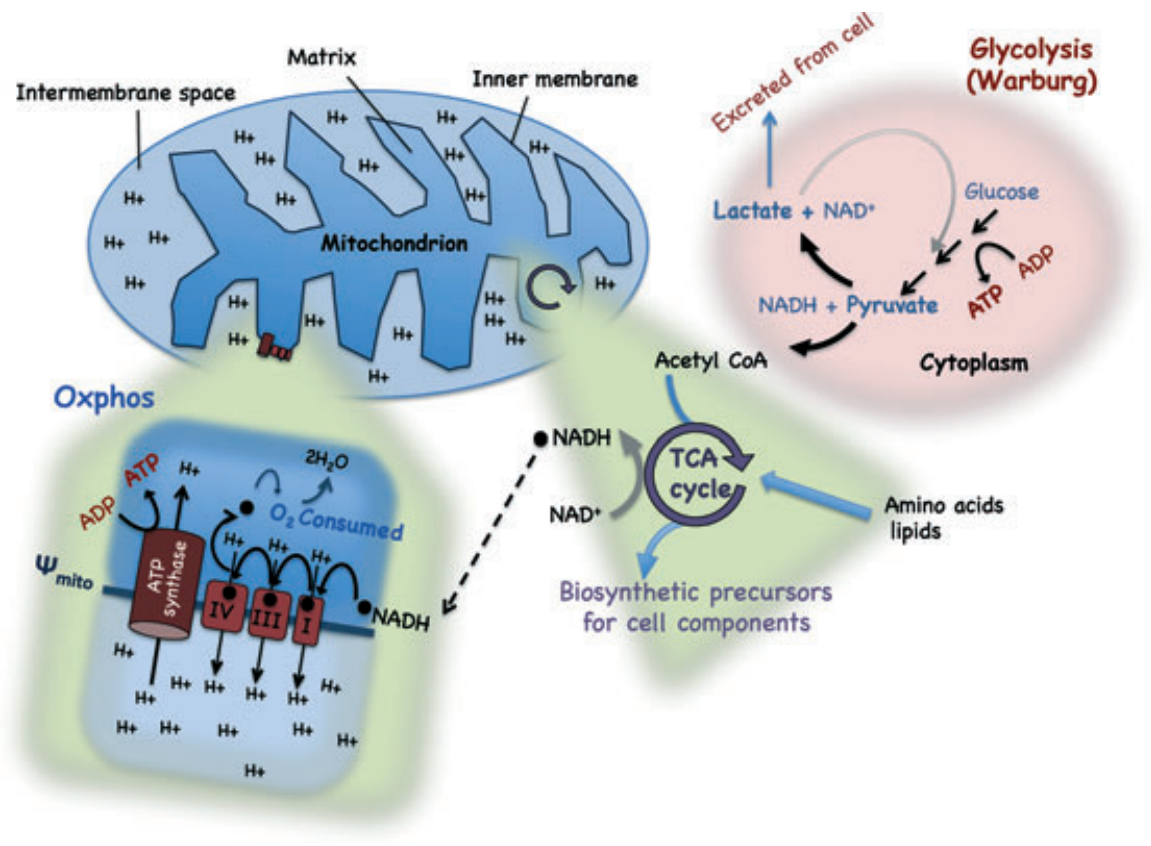

Fig. 1. ATP-generating metabolic pathways. Quiescent $\mathrm{T}$ cells mainly use oxidative phosphorylation (OXPHOS) to generate ATP, a process that takes place in mitochondria. A variety of substrates, such as glucose, amino acids, and lipids, are oxidized in the TCA cycle; these reactions generate biosynthetic precursors as well as the reducing agents NADH. The NADH coenzyme, which is used in many biochemical reactions, donates electrons to the electron transport chain for OXPHOS. Upon activation, T cells upregulate glycolysis, the process in which glucose is converted into pyruvate, thereby generating ATP and reducing $\mathrm{NAD}^{+}$to NADH. To fuel OXPHOS, pyruvate can be shuttled into the TCA cycle; however, during Warburg metabolism, the majority of pyruvate is converted into lactate, which is excreted from the cell. In the process of converting pyruvate to lactate, $\mathrm{NADH}$ is oxidized to $\mathrm{NAD}^{+}$, which in turn can support continued glycolysis. 


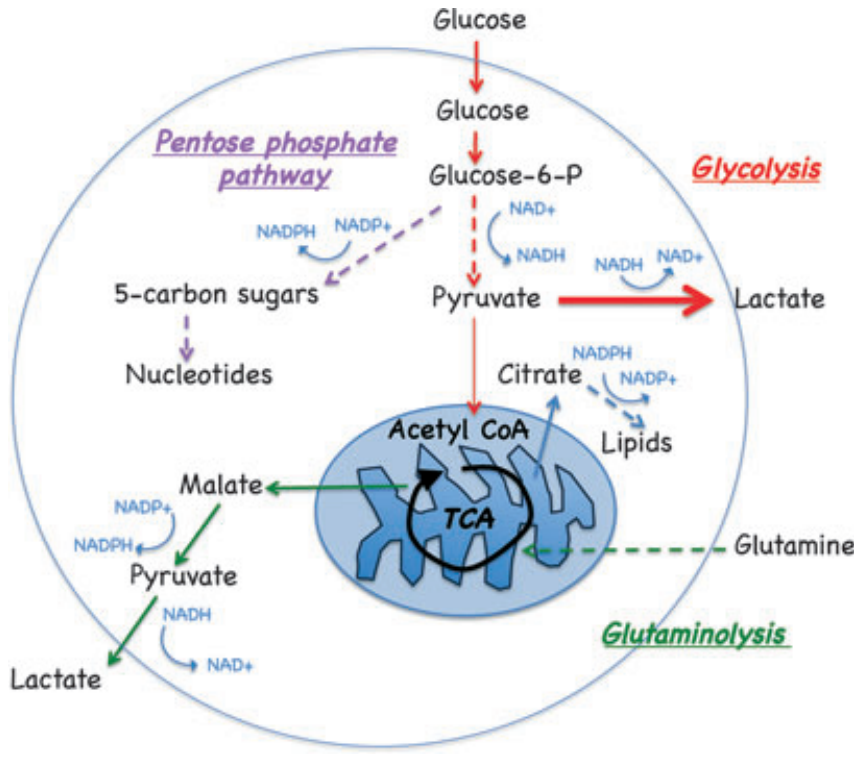

Fig. 2. Metabolic pathways in activated $\mathrm{T}$ cells. Activated $\mathrm{T}$ cells use glucose and glutamine as their main nutrients to support rapid proliferation and effector functions. Glucose uptake is dependent on glucose transporter expression, and once inside the cell, glucose is converted into glucose-6-phosphate. This intermediate is the starting point for glycolysis, which ultimately leads to the production of pyruvate. In Warburg metabolism, the majority of pyruvate is excreted as lactate. Glutamine uptake and metabolism is also critical in activated $\mathrm{T}$ cells. As proliferation requires rapid synthesis of macromolecules for the generation of daughter cells, biosynthetic intermediates provided by the TCA cycle are necessary to support this process. Citrate from the TCA cycle can be excreted into the cytosol and used for lipid synthesis. Lipid synthesis also requires reductive power in the form of NADPH. $\mathrm{NADPH}$ is generated by the conversion of malate, excreted from the mitochondria, into pyruvate. Alternatively, using glucose-6-phosphate in the pentose phosphate pathway also generates NADPH. This latter pathway is important for nucleotide synthesis. Dashed arrows indicate multiple steps. Red, green, and purple arrows indicate glycolysis, glutaminolysis, and pentose phosphate pathways, respectively.

whereas transgenic expression of Glut1 leads to enhanced IL-2 and IFN- $\gamma$ production (18). Also, in the absence of glucose, $\mathrm{CD}^{+} \mathrm{T}$ cells have a defect in cytolytic activity marked by reduced granzyme and perforin production (19). Collectively, many studies illustrate that glucose is an essential nutrient for $\mathrm{T}$ cells.

Once inside the cell, glucose is degraded and used to (i) generate energy, either through Warburg metabolism or the TCA cycle and OXPHOS, and (ii) to provide the building blocks for cellular maintenance and proliferation (Fig. 1). To produce ATP from OXPHOS, glucose is converted to pyruvate via the glycolytic pathway and then to acetyl CoA, where it can enter the TCA cycle by condensing with oxaloacetate (Fig. 2). TCA cycle reactions generate the reduced coenzyme $\mathrm{NADH}$, which acts as an electron donor for the electron transport chain (ETC.), fueling ATP production through OXPHOS. Glycolysis can also generate ATP in the cytoplasm via substrate level phosphorylation. Here, glucose is not fully oxidized in the mitochondria, even though there is sufficient oxygen present to do so (Warburg effect), but rather glucose-derived pyruvate is converted to lactate in the cytoplasm and excreted from the cell. Lactate excretion supports continued Warburg metabolism by regenerating $\mathrm{NADH}$ to $\mathrm{NAD}^{+}$, a coenzyme that facilitates earlier steps of glucose breakdown (2) (Fig. 1). As an alternative to glycolysis, glucose-derived glucose-6-phosphate can be directed into the pentose phosphate pathway (Fig. 2). The pentose phosphate pathway is important for proliferating cells as it provides precursors for the synthesis of nucleotides and aromatic amino acids, as well as reducing equivalents in the form of NADPH. NADPH is required to maintain the pool of reduced glutathione, as well as to support lipid and cholesterol synthesis (Fig. 2).

\section{Glutamine and proliferating $T$ cells}

In addition to the switch to glycolysis, several other metabolic pathways are altered upon T-cell activation. Changes include decreased fatty acid oxidation, decreased pyruvate flux into the TCA cycle, increased glucose flux into the pentose phosphate pathway, and increased glutamine metabolism $(21,25,26)$ (Fig. 2). Similar to glucose uptake, growth factor signaling controls the import of glutamine into the cell. It was recently shown that in an IL-3-dependent cell line glutamine uptake is dependent on glucose flux through the hexosamine pathway (27). The IL-3 receptor, like receptors for other growth factor cytokines, is a glycoprotein whose surface expression is dependent on glucose availability for glycosylation, thus providing an explanation as to why in certain settings glucose is essential for mammalian cells even when there is an abundant supply of amino acids available (28). Glutamine uptake and metabolism has been shown to be critical for T-cell function $(7,20)$. Metabolism of glutamine, termed glutaminolysis in analogy to glycolysis, is an energy-producing pathway. In contrast with glycolytic energy production, glutaminolytic energy production requires mitochondrial OXPHOS (3). In addition to energy, proliferating $\mathrm{T}$ cells, much like tumor cells, require the rapid synthesis of macromolecules that can be incorporated into cellular machinery and membrane components to form daughter cells. Synthesis of macromolecules requires biosynthetic intermediates, which are provided by the TCA cycle through the conversion of metabolites such as pyruvate and glutamine.

As described earlier, pyruvate derived from glycolysis is converted into acetyl CoA, which condenses with oxaloacetate 
to generate citrate. Glutamine can enter the TCA via conversion to $\alpha$-ketoglutarate, which can also be processed to oxaloacetate and subsequently citrate. To generate new lipids, citrate has to be excreted into the cytosol, where it can be converted to acetyl CoA, the backbone for lipid synthesis (29) (Fig. 2). Thus, both glucose and glutamine can be used as carbon sources for lipid synthesis. Cells must be capable of rapidly replenishing TCA cycle intermediates if any are drawn off for biosynthesis. Under normoxic conditions, most of the carbon for fatty acid synthesis is derived from glucose; however, glutamine is also important for lipid synthesis, as it replenishes oxaloacetate for continued TCA cycle function $(23,30-$ 32 ). In addition to carbon, reductive power in the form of $\mathrm{NADPH}$ is required for lipid synthesis (29). Along with $\mathrm{NADPH}$ production from the pentose phosphate pathway, $\mathrm{NADPH}$ is also produced during glutaminolysis when glutamine is metabolized in the TCA cycle to pyruvate and then converted into lactate (31) (Fig. 2). The need for NADPH to support lipid and nucleotide biosynthesis as well as for maintenance of reduced glutathione may explain why the majority of glutamine-derived carbon is excreted as lactate in rapidly proliferating cells (31). In addition, high rates of glutamine metabolism in proliferating cells results in excess intracellular nitrogen that must be secreted as alanine or ammonia to avoid toxicity (29). Glutamine also provides a nitrogen source for non-essential amino acids and nucleotides $(31,33)$.

\section{Quiescent T cells}

Much more is known about the metabolic pathways that support T-cell activation and proliferation than the metabolic pathways that support T-cell quiescence. Naive and memory T cells are smaller than activated $\mathrm{T}$ cells, have decreased metabolic activity that is primarily catabolic in nature, and are more resistant to apoptosis than activated cells (34). The conventional view suggests that quiescent $\mathrm{T}$ cells interchangeably break down glucose, amino acids, and fatty acids to fuel the TCA cycle and generate ATP in their mitochondria via OXPHOS $(1,4)$. Although TCR stimulation and CD28 costimulation are required for the switch from a quiescent metabolism to the glycolytic metabolism of an activated cell $(7,18)$, it has been shown that maintaining quiescence in naive $\mathrm{T}$ cells is not simply due to a lack of these signals but is an active process that involves metabolic regulation (34-36).

\section{Regulation of metabolic pathways in $\mathrm{T}$ cells}

The factors that regulate metabolism in cells are highly interconnected. Given the fundamental role of metabolism in virtually every cellular process, there has been accumulat- ing interest in how T-cell metabolism is controlled during different phases of T-cell differentiation. For organizational purposes, we have chosen to discuss some of the latest findings in this field as they pertain to naive $\mathrm{T}$ cells, effector $\mathrm{T}$ cells, and memory $\mathrm{T}$ cells independently.

\section{Naive T cells \\ KLF and Fox transcription factors}

Naive $\mathrm{T}$ cells maintain a catabolic metabolism, which is actively enforced (34-36). The Forkhead box (Fox) and Kruppel-like family of transcription factors (KLF) are thought to be responsible for T-cell quiescence by inducing inhibitors of cellular activation (34). Several recent studies have suggested that Fox and KLF2 transcription factors indirectly maintain quiescence by regulating the survival and migration of $\mathrm{T}$ cells (37-40) (Fig. 3). A study by Takada et al. (40) showed that KLF2-deficient $\mathrm{CD}^{+}{ }^{+} \mathrm{T}$ cells had only a minimal defect in cell cycle control and displayed normal proliferative capacity. However, expression of the homing receptors $\mathrm{S}_{1} \mathrm{P}_{1}$ and CD62L were decreased and thus trafficking of $\mathrm{T}$ cells in vivo was impaired (40). In another study (41), T cells deficient in

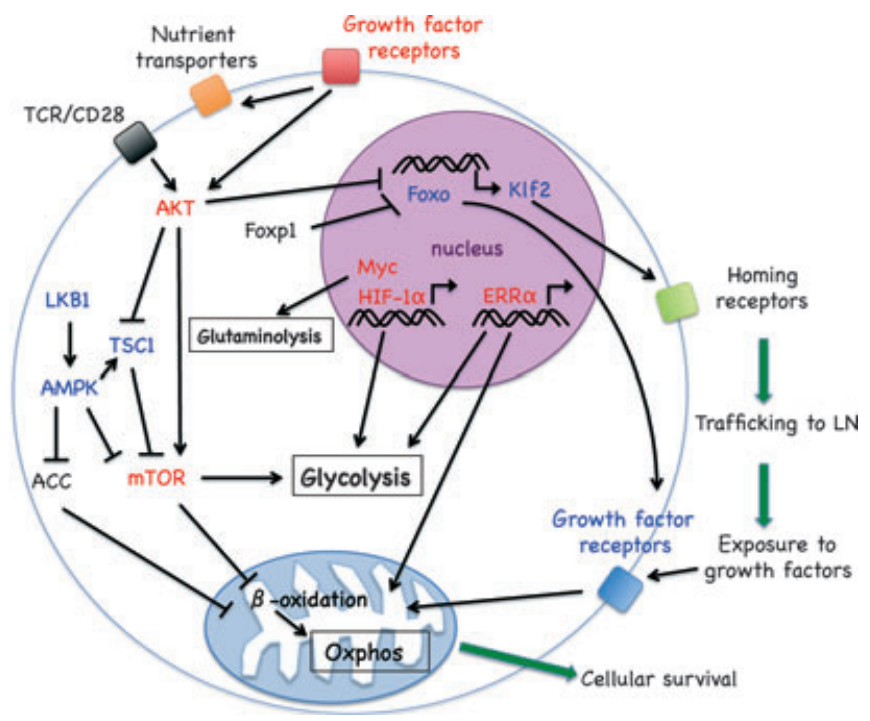

Fig. 3. Factors regulating metabolism in $\mathbf{T}$ cells. Metabolism has a fundamental role in virtually every cellular process, and there has been a growing interest in how metabolic pathways regulate $\mathrm{T}$-cell function and fate. This diagram highlights some of the factors recently described in the literature to regulate metabolism in quiescent and activated T cells. Factors promoting anabolic pathways support the metabolic needs of $\mathrm{T}$ cells during activation and proliferation (red) Factors that regulate quiescence maintain catabolic mitochondrial metabolism and promote cell survival and persistence (blue). Depending on the context, signaling through growth factor receptors (red) can drive proliferation and effector T-cell differentiation (e.g. IL-2 signals), or promote survival (blue) through enhanced mitochondrial function (e.g. IL-15 and IL-7 signals). 
the transcription factor ELF4 showed reduced KLF2 and KLF4 expression, which resulted in diminished CD62L expression and increased homeostatic and antigen-driven proliferation, respectively (41). It was later shown by the same group that mTOR signaling, which is induced during $\mathrm{T}$-cell activation (Fig. 3), inhibits ELF4 expression in activated $\mathrm{CD} 8^{+} \mathrm{T}$ cells, releasing them from their quiescent state (42). Altered homing receptor expression changes trafficking patterns of naive $\mathrm{T}$ cells and thereby affects exposure to growth factors and subsequently the metabolic pathways in these cells.

Foxo1 has been found to be essential for IL-7R $\alpha$ expression in peripheral T cells (38), and IL-7 signaling is critical for naive T-cell survival $(43,44)$ (Fig. 3 ). In line with these observations, it was recently shown that inactivation of Foxo1 was essential for effector differentiation of $\mathrm{CD}^{+} \mathrm{T}$ cells, a process regulated through the transcription factor T-bet and the mTOR kinase (45). In fasted muscle cells, Foxo1 is activated and will suppress glucose oxidation (46) while enhancing surface levels of the fatty acid translocase FAT/CD36 (47) and thus promoting fatty acid uptake and oxidation. These data suggest that Foxo1 prepares the muscle cell for the increased reliance on fatty acid metabolism that is characteristic of fasting and is consistent with the idea that Foxo1 is contributing to the maintenance of metabolic quiescence in naive $\mathrm{T}$ cells. Interestingly, a different Fox factor, Foxp1, has been demonstrated to compete with Foxo1 for the control of IL-7R $\alpha$ expression, and loss of Foxp1 induced naive $\mathrm{T}$ cells to gain an effector phenotype (48). Whereas normal naive $\mathrm{T}$ cells do not proliferate in response to IL-7 (49), when Foxp1 was lost, IL-7R $\alpha$ expression increased and proliferation was induced. In addition to promoting IL-7R $\alpha$ expression, Foxp1 deficiency induced other changes, including enhanced Erk activation, and inhibition of Erk and MEK severely attenuated the proliferative response of Foxp1 deficient T cells. Thus, Foxp1 appears to affect more than one pathway to maintain naive T-cell quiescence (48).

MST1 is a kinase that directly activates FOXO transcription factors. The MST/FOXO pathway has been shown to mediate oxidative stress responses and extend lifespan in both mammalian neurons and nematodes (50). A recent study reported a primary immunodeficiency phenotype in humans that was associated with the loss of MST1 function and primarily characterized by a progressive decline in naive $\mathrm{T}$ cells (51). In T cells, MST-1 was necessary for Foxo1 protein stability and expression, and indeed IL-7R $\alpha$ and CD62L expression was impaired on $\mathrm{T}$ cells from these patients (51). In line with impaired IL-7R signaling, Bcl-2 expression levels were low and cell survival was diminished in MST-deficient $\mathrm{T}$ cells (51). Collectively, these observations indicate that effective maintenance of T-cell quiescence and survival is likely a balanced interplay between regulating metabolism and apoptosis, activation, and migration of naive $\mathrm{T}$ cells.

Tsc and mTOR

Several recent studies investigated the role of the tumor suppressor Tsc1, a regulator of the mTOR pathway, in maintaining naive T-cell quiescence (Fig. 3). It was found that Tsc1 established a quiescent gene-expression program linking cell cycle and metabolism with the expression of immune response genes in T cells (35). T cells that lacked Tsc1 were larger and proliferated more than control $\mathrm{T}$ cells, indicating a loss of quiescence and a more activated state, which resulted from increased mTORC1 activation $(35,52)$. Loss of Tcs 1 also led to more ROS production and thus enhanced apoptosis and lower numbers of peripheral $\mathrm{T}$ cells $(35,36,52,53)$. Unexpectedly, although Tsc1 deficiency caused hyperactive responses to TCR stimulation in vitro, expansion of Tsc1-deficient $\mathrm{CD}^{+} \mathrm{T}$ cells upon bacterial infection in vivo was impaired, demonstrating that maintenance of T-cell quiescence is important for a productive immune response (35). Failure to mount an efficient T-cell response in vivo was also observed when the excessive apoptosis evident in Tsc1-deficient $\mathrm{T}$ cells was blocked by transgenic expression of $\mathrm{Bcl} 2$, suggesting that Tsc1 deficiency impairs T-cell responses through a mechanism that is largely independent of cell survival. It was previously shown that hematopoietic stem cells (HSCs) deficient for Tsc1 have increased expression of many mitochondrial genes and higher rates of OXPHOS that leads to increased levels of ROS (54). Loss of Tsc1 function resulted in reduced hematopoiesis and self-renewal of HSCs. Treatment with a ROS antagonist in vivo restored HSC numbers and function, suggesting that the Tsc1mTOR pathway serves to suppress mitochondrial respiration and ROS production, and thereby maintains quiescence in hematopoietic stem cells (54). In a separate study, it was also shown that scavenging ROS decreased cell death of Tsc1-deficient peripheral $\mathrm{CD}^{+}{ }^{+} \mathrm{T}$ cells (36). Together, these studies illustrate how the Tsc1-mTOR pathway maintains quiescence by regulating cellular metabolism.

\section{LkbI and AMPK}

Evidence is emerging that the liver kinase B1 (LKB1) is also important in controlling T-cell metabolism and quiescence (Fig. 3). LKB1 is a serine/threonine kinase and is part of an evolutionarily conserved energy-sensing pathway $(55,56)$. It was first identified as the tumor repressor responsible for Peutz-Jeghers syndrome (57) and was recently described to 
regulate quiescence and metabolism in hematopoietic stem cells (58-60). LKB1 can exert its effects on cellular metabolism via the phosphorylation of the $\alpha$ subunit of AMPactivated protein kinase (AMPK), and AMPK activation by LKB1 is essential under conditions of bioenergetic stress $(61,62)$. AMPK has a central role in the regulation of energy homeostasis by mediating glucose, protein, and fatty acid metabolism (63). In contrast with the P13K/AKT/ mTOR pathway, which promotes anabolism, AMPK supports catabolism and inactivates growth-inducing pathways. As quiescent cells have a catabolic metabolism and mostly use OXPHOS for their energy, the regulatory effects of AMPK in quiescent cells are likely to merge with the oxidation of fatty acids to supply energy needs. Activation of AMPK can promote the oxidation of fatty acids in two ways $(64,65)$ : through suppression of mTOR activity (66) and by phosphorylating and thereby inactivating acetyl-CoA carboxylase (ACC) $(67,68)$ (Fig. 3). Although it was shown that AMPK was not the critical effector of LKB1 in the maintenance of hematopoiesis (58-60), LKB1 regulated mitochondrial function is at least partly AMPK dependent $(58,60)$. Recently, it was found that LKB1 is essential for the survival of thymocytes and development of T-cell progenitors $(69,70)$ and is required for $\mathrm{CD}^{+}$and $\mathrm{CD}^{+}$T-cell development and peripheral homeostasis (71). LKB1-deficient peripheral $\mathrm{T}$ cells were shown to have enhanced glucose uptake and a higher glycolytic rate (71), whereas LKB1-deficient thymocytes were shown to have reduced expression of the CD98 subunit of the amino L-acid transporter (70). These results suggest that LKB1 is critical for matching metabolism to energy demand and in this way acts as an important regulator of cellular quiescence. Future studies are required to further elucidate the role of MTOR and AMPK signaling in maintaining quiescence in $\mathrm{T}$ cells and its precursors.

\section{Effector $\mathrm{T}$ cells}

AKT, LKBI, and AMPK

$\mathrm{T}$ cells increase their metabolism in response to immune stimulation via the serine-threonine kinase AKT $(7,8)$ (Fig. 3). AKT is rapidly activated in response to TCR triggering or common $\gamma$-chain cytokines, such as IL-2 and IL-15 (72-75). However, it was recently reported that AKTindependent pathways also control T-cell metabolism, survival, and proliferation (76). AKT was shown to be dispensable for the regulation of glucose uptake in effector $\mathrm{CD}^{+} \mathrm{T}$ cells (77) but rather maintained a critical role in $\mathrm{T}$-cell effector functions by regulating the expression of cytolytic molecules and the repertoire of cytokine/chemokine-receptors and adhesion molecules (77). In addition to describing the role of LKB1 in controlling cellular quiescence, a recent study by MacIver et al. (71) investigated the role of LKB1 in T-cell development and peripheral function. In response to activation, $\mathrm{LKB} 1$-deficient $\mathrm{T}$ cells displayed defects in proliferation, viability, and altered metabolism. Loss of LKB1 resulted in enhanced glycolytic gene expression and impaired oxidation of lipids in response to metabolic stress induced by IL-2 withdrawal. In line with enhanced glucose metabolism, LKB1-deficient $\mathrm{T}$ cells had greater expression of surface activation markers and increased production of IFN- $\gamma$. Furthermore, $\mathrm{T}$ cells deficient for AMPK displayed similar defects in activation, metabolism, and cytokine production. As expected, both LKB1 and AMPK- $1 \alpha$-deficient $\mathrm{T}$ cells showed increased phosphorylation of mTOR targets, and rapamycin blocked the enhanced IFN- $\gamma$ production in these cells (71). This study demonstrates that the metabolic effects of LKB1 and AMPK are mTOR dependent (71) and highlights the multifaceted role of these proteins in regulating $\mathrm{T}$-cell development and function through metabolism.

\section{HIF-I and Myc}

Recently, the metabolism of various $\mathrm{CD} 4^{+}$T-cell subsets has been explored. It was shown that upon activation, Th1, Th2, Th17, and Treg cells all increased their glycolytic rates but that this occurred to a much greater extent in Th1, Th2, and Th17 cells than in Treg cells $(78,79)$. Hypoxia inducible factor $1 \alpha(\mathrm{HIF}-1 \alpha)$ is a transcription factor that regulates the expression of genes that encode for glycolytic enzymes (80) as well as downregulates mitochondrial oxygen consumption by blocking the entrance of pyruvate in the TCA cycle (81) (Fig. 3). A recent study showed that HIF- $1 \alpha$ was strongly induced in Th17 cells but not in Th1 or Th2 cells and that Th17 cell differentiation in vitro and in vivo was impaired in the absence of this transcription factor (79). These results demonstrated that HIF-1 $\alpha$ controls the glycolytic activity that is essential for Th17 cell development. Interestingly, the addition of fatty acids to Th1, Th2, and Th17 cells suppressed lineage-specific cytokine production (78). Although this effect appeared to be at least in part due to enhanced cell death, precisely how fatty acids impair viability and cytokine production in these cells remains to be determined. In addition to the idea that the presence of a lipid fuel source alters cellular metabolism from glycolysis to lipid oxidation, it is also possible that the 
presence of fatty acids results in signaling that is not compatible with the glycolytic program of these cells. Alternatively, lipids could be promoting lipotoxicity, as nonadipose tissues have a limited capacity to store lipids, that when exceeded, cellular dysfunction and death may result (82). In contrast with $\mathrm{CD}^{+}{ }^{+}$effector $\mathrm{T}$ cells, Treg cells demonstrated high rates of fatty acid oxidation, and blocking this type of metabolism impaired Treg development (78). Inhibiting mTOR with rapamycin also resulted in an increased frequency of Treg cells, an effect that was dependent on fatty acid oxidation (78). In line with this finding, Treg cells demonstrated elevated AMPK activation when compared with effector and naive $\mathrm{CD} 4^{+} \mathrm{T}$ cells, and administration of the AMPK activator metformin reduced Glut1 expression, promoted fatty acid oxidation, and increased the percentage and number Treg cells (78). Together these results demonstrate that HIF- $1 \alpha$ is essential for Th17 cell development and associated glycolytic metabolism, while the absence of HIF- $1 \alpha$ drives Treg cell differentiation and fatty acid oxidation.

In contrast with the findings by Shi et al. (79) showing that HIF- $1 \alpha$ was strongly and selectively induced only in the Th17 cells subset, a recent study by Wang et al. (21) showed that HIF- $1 \alpha$ expression was highly induced upon activation in a mixed culture of $\mathrm{CD}^{+}$and $\mathrm{CD} 8^{+} \mathrm{T}$ cells. Despite its quick induction, HIF- $1 \alpha$ appeared dispensable for the initiation of metabolic changes and activation-associated proliferation in these $\mathrm{T}$ cells (21). This study went on to show that Myc, a transcription factor that regulates glycolytic metabolism in transformed cells $(83,84)$, was highly induced upon T-cell activation, and its expression was required for activation-induced metabolic programming (21) (Fig. 3). Acute Myc deletion inhibited proliferation and cell growth upon T-cell activation, while leaving AKT and ERK signaling pathways intact. Consistent with the important role for glycolysis and glutaminolysis in T-cell activation, Myc-deficient $\mathrm{T}$ cells showed impaired activationinduced glycolysis and glutaminolysis and decreased activation of the downstream targets of mTOR. Furthermore, Myc-driven glutaminolysis was tightly coupled to the biosynthesis of polyamines that are essential for T-cell proliferation (21). In agreement with these findings, Carr et al. (20) recently showed that $\mathrm{T}$ cells grown without glutamine did not increase in size to the same extent as in cells cultured in media with glutamine, implicating that this amino acid is essential for optimal cell growth. Interestingly, in renal carcinoma cells and fibroblasts, other effects of Myc and HIF- $1 \alpha$ signaling have been described. It has been shown that Myc stimulates nuclear-encoded mitochondrial genes and mitochondrial biogenesis (85), and HIF- $1 \alpha$ inhibits these changes (86). Although metabolic processes in cancer cells can closely mimic those in activated $\mathrm{T}$ cells, future studies in $\mathrm{T}$ cells are required to determine the relative expression and dominance of Myc and HIF- $1 \alpha$ upon activation and how this may affect mitochondrial changes.

mTOR

The conserved kinase mTOR has a central role in the regulation of metabolism by sensing and integrating signals in response to nutrients, growth factors, energy, and stress (87) (Fig. 3). mTOR is present in two distinct complexes: mTOR complex 1 (mTORC1) and mTORC2 (88). It was previously shown that mTOR signaling is required for $\mathrm{CD} 4^{+}$ effector T-cell differentiation, as mTOR-deficient $\mathrm{T}$ cells fail to develop into Th1, Th2, and Th17 cells both in vitro and in vivo. However, mTOR-deficient $\mathrm{T}$ cells do differentiate into Treg cells (89). More recently it was shown by this same group that mTORC1 signals specifically regulate Th1 and Th17 lineage differentiation, whereas mTORC2 signaling drives Th2 development (90). In line with their previous observation, inhibition of both mTORC1 and mTORC2 was required for spontaneous Treg induction (90). These studies provide a strong link between metabolic control and $\mathrm{CD} 4^{+}$ T-cell differentiation. Future studies are needed to further elucidate the pathways by which mTORC1 and mTORC2 differentially affect helper T-cell development and metabolism.

\section{$E R R \alpha$}

Another important regulator of transcription of metabolic genes is the nuclear hormone receptor, estrogen-related receptor- $\alpha \quad($ ERR- $\alpha) \quad(91,92) \quad$ (Fig. 3). Recently, it was shown that this protein acts as a metabolic regulator of effector $\mathrm{CD}^{+}{ }^{+} \mathrm{T}$-cell homeostasis and function by broadly affecting metabolic gene expression and glucose metabolism (93). ERR- $\alpha$-deficient $\mathrm{CD}^{+}{ }^{+} \mathrm{T}$ cells exhibited reduced activation and proliferation, which was accompanied by impaired glucose uptake and mitochondrial metabolism. Consistent with these observations in $\mathrm{T}$ cells, it was recently shown that the expression of the Drosophila ortholog of ERR mid-embryogenesis induced a switch in gene expression that promoted a metabolic program associated with proliferating cells, supporting the dramatic growth that occurs during larval development (94). Interestingly, the failure of $\mathrm{T}$ cells to become activated in the presence 
of an ERR- $\alpha$ inhibitor was a result of impaired glucose metabolism, as this defect was rescued by the addition of exogenous fatty acids, but not pyruvate, indicating that ERR- $\alpha$ positively regulates pyruvate flux into the TCA cycle. This illustrates that mitochondrial metabolism, and not only glycolysis, is important for the early phase of $\mathrm{T}$ cell activation. This is consistent with another study showing that mitochondrial biogenesis is induced in the early phase after TCR activation (95). The inability to direct pyruvate into the TCA cycle may lead to decreased lipid synthesis and cell growth and thus impaired activation and proliferation. Although fatty acid oxidation could rescue $\mathrm{CD} 4^{+}$T-cell proliferation during initial activation, lipids were not sufficient to optimally restore cell division and effector function of Th1, Th2, and Th17 cells upon ERR- $\alpha$ inhibition. However, as would be expected from cells that mainly use lipid metabolism, Treg cells were efficiently generated in the presence of an ERR- $\alpha$ inhibitor. As ERRs have been shown to associate with HIF- $1 \alpha$ and regulate its function in tumors (96), future studies will need to determine how nuclear hormone receptors and transcription factors like $\mathrm{HIF}-1 \alpha$ and $\mathrm{Myc}$ interact in $\mathrm{CD} 4^{+} \mathrm{T}$ cells.

\section{Targeting effector T-cell metabolism for immunotherapy}

Implicit in the fact that metabolism underlies the functional capacity of $\mathrm{T}$ cells is the idea that manipulating $\mathrm{T}$-cell metabolism in vivo will alter the outcome of adaptive immune responses. In a recent study, the bioenergetics of alloreactive $\mathrm{T}$ cells was examined (97). It was found that bone marrow cells that were transplanted into irradiated syngeneic hosts proliferated and adopted a glycolytic metabolism, as evidenced by increased Glut1 expression and lactate production when compared with naive bone marrow cells. Oxygen consumption by these cells, however, was unaffected, suggesting that glycolysis was the predominant form of metabolism rather than OXPHOS in bone marrow cells transplanted into irradiated syngeneic hosts. In contrast, lymphocytes that proliferated in response to alloantigens in a model of graft versus host disease (GVHD) also showed increased Glut1 expression and lactate production but had elevated oxygen consumption levels as well. Although large increases of intracellular acylcarnitines suggested changes in fatty acid metabolism, it was not directly determined if fatty acid oxidation was responsible for the increase in oxygen consumption. It was also observed that when compared with the transplanted bone marrow cells, alloreactive $\mathrm{T}$ cells proliferated faster, had decreased amounts of glutathione, hyperpolarized mitochondrial membrane potential, and increased superoxide levels. Use of Bz-423, a compound that promotes superoxide production by inhibiting the mitochondrial $\mathrm{F}_{1} \mathrm{~F}_{0}$-ATPase, selectively induced apoptosis in alloreactive $\mathrm{T}$ cells but not resting $\mathrm{T}$ cells or proliferating bone marrow cells. The authors speculate that this was most likely a result of the lack of sufficient anti-oxidant reserves in the alloreactive cells to cope with increased superoxide. Importantly, Bz-423 has therapeutic potential, as its use arrested ongoing GVHD by selectively inducing apoptosis in the alloreactive $\mathrm{T}$ cells. This study highlights the value of targeting T-cell metabolism for therapeutic benefit. To what extent the bioenergetics of alloreactive $\mathrm{T}$ cells differs from $\mathrm{T}$ cells activated by an infection or cancer needs further exploration.

\section{Memory T cells}

Fatty acid oxidation and memory $T$ cells

The metabolic demands of proliferating $\mathrm{T}$ cells in culture have been studied extensively, and the importance of glucose is well documented. Much less is known about metabolic requirements of memory $\mathrm{T}$ cells. Several years ago we published a study showing that $\mathrm{CD}^{+} \mathrm{T}$ cells that lacked TRAF6 were impaired in their ability to form a stable population of antigen-specific memory $\mathrm{T}$ cells after bacterial infection, and microarray analysis suggested that this was due to defects in several catabolic pathways of metabolism, including fatty acid oxidation (98). We demonstrated that augmenting fatty acid oxidation in $\mathrm{CD}^{+} \mathrm{T}$ cells by treating mice with either the AMPK activator metformin or the mTOR inhibitor rapamycin, two drugs that are known to induce fatty acid oxidation, promoted the development of memory $\mathrm{CD}^{+} \mathrm{T}$ cells after immunization (64-68). This study was the first to suggest that targeting catabolic pathways of metabolism, such as fatty acid oxidation, after vaccination could enhance the development of stable $\mathrm{CD} 8^{+} \mathrm{T}$ cell memory. Our findings showing that rapamycin promoted $\mathrm{CD}^{+}$T-cell memory development were supported by another study published at the same time demonstrating that this drug also promoted immunity to viral infection (99). Importantly, this study by Araki et al. (99) established mTOR as a cell-intrinsic regulator of $\mathrm{CD} 8^{+}$T-cell memory development. As rapamycin is traditionally used clinically for its immuosuppressive properties, these findings generated considerable interest. 
Focusing on this ability of rapamycin to enhance immunity, it was more recently shown by Rao et al. (100) that $\mathrm{CD} 8{ }^{+} \mathrm{T}$ cells activated and cultured in the presence of rapamycin for 3 days and subsequently transferred into recipient mice formed better memory $\mathrm{T}$ cells in terms of quantity and quality in comparison with control $\mathrm{T}$ cells. Furthermore, it was found that mTOR regulated the expression of the transcription factors T-bet and Eomesodermin, which are known to direct effector and memory $\mathrm{CD} 8^{+} \mathrm{T}$-cell fates, respectively (100-103), further illustrating how this central metabolic regulator specifies T-cell fate. Interestingly, a recent paper from this same laboratory (45) showed that the ability of rapamycin to augment $\mathrm{CD} 8^{+}$memory $\mathrm{T}$-cell development was ablated when Foxo1 was silenced. Inactivation of Foxo1 appeared to be important for T-bet mediated effector functions, whereas active Foxo1 resulted in a switch to more Eomesodermin transcription factor activation, and more $\mathrm{CD} 8^{+}$ memory precursor $\mathrm{T}$ cells. Given these findings, it will be interesting to determine whether Eomesodermin regulates the expression of metabolism genes that dictate a quiescent phenotype in $\mathrm{CD} 8{ }^{+} \mathrm{T}$ cells.

\section{Mitochondrial spare respiratory capacity}

Research in our laboratory continues to focus on the role of metabolism in the development of memory $\mathrm{CD} 8^{+} \mathrm{T}$ cells after infection. In a recent study (104), we showed that memory $\mathrm{CD}^{+} \mathrm{T}$ cells maintain significant mitochondrial spare respiratory capacity (SRC) in comparison with naive or effector $\mathrm{T}$ cells. SRC is the extra mitochondrial capacity available in a cell to produce energy under conditions of increased work or stress and is thought to be important for long-term cellular survival and function (105-109). We found that greater SRC was underscored by enhanced mitochondrial biogenesis in memory $\mathrm{CD} 8^{+} \mathrm{T}$ cells, and that this process was modulated by IL-15. In addition, we demonstrated that SRC was abrogated when carnitine palmitoyltransferase 1a (CPT1a), the mitochondrial protein that is the rate-limiting step for $\beta$-oxidation of fatty acids in the mitochondria (110-112) was inhibited. Our findings led us to a model where bioenergetics regulates memory $\mathrm{T}$-cell development after infection (Fig. 4). As effector $\mathrm{CD} 8^{+} \mathrm{T}$ cells rapidly proliferate during an immune response, they primarily use glycolysis to support bioenergetic needs. We speculate that during this process, the majority of $\mathrm{CD}^{+}$effector $\mathrm{T}$ cells fail to maintain and/or induce mitochondrial biogenesis resulting in a reduction in the ratio between mitochondrial mass

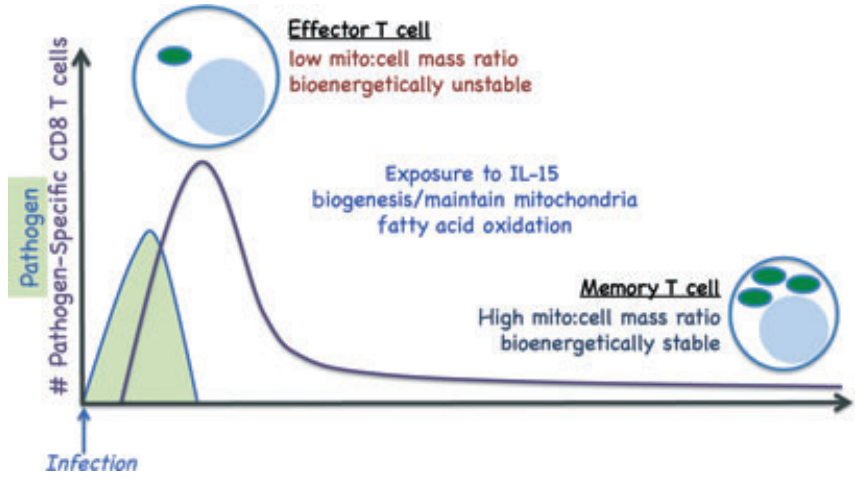

Fig. 4. Bioenergetic model of memory $\mathrm{CD}^{+}{ }^{+} \mathrm{T}$-cell survival after infection. As effector $\mathrm{CD} 8^{+} \mathrm{T}$ cells rapidly proliferate during an immune response, they primarily use glycolysis to support bioenergetic needs. We speculate that during this process, the majority of $\mathrm{CD} 8^{+}$ effector $\mathrm{T}$ cells fail to maintain and/or induce mitochondrial biogenesis resulting in a reduction in the ratio between mitochondrial mass and overall cell mass and thereby lose reserve energy-generating capacity, i.e. spare respiratory capacity. Reduced mitochondrial mass increases dependence on glycolysis and renders effector $\mathrm{T}$ cells bioenergetically unstable due to a decline in their ability to create energy from diverse substrates via OXPHOS, and thus are unable to maintain viability when infection-associated signals decline and elements such as IL-2 that support glycolysis dissipate. Some antigenspecific $\mathrm{T}$ cells from the primary infection survive as long-lived memory $\mathrm{T}$ cells, because these cells have maintained mitochondrial mass via exposure to IL-15 or other growth factor cytokines. More mitochondrial mass allows greater use of fatty acids for energy via OXPHOS, thereby facilitating cell survival in the absence of proglycolysis signals. Moreover, the enhanced spare respiratory capacity provided by increased mitochondrial mass might allow memory $\mathrm{T}$ cells to respond quickly if pathogen is reencountered.

and overall cell mass, and thereby lose reserve energygenerating capacity, i.e. SRC. Reduced mitochondrial mass increases dependence on glycolysis and renders effector $\mathrm{T}$ cells bioenergetically unstable due to a decline in their ability to create energy from diverse substrates (e.g. fatty acids) via OXPHOS, and thus are unable to maintain viability when infection-associated signals decline and elements such as IL-2 that support glycolysis dissipate. Some antigen-specific $\mathrm{T}$ cells from the primary infection survive as long-lived memory $\mathrm{T}$ cells, because these cells have maintained mitochondrial function via exposure to IL-15 or other growth factor cytokines. More mitochondrial mass allows greater use of fatty acids for energy, thereby facilitating cell survival in the absence of pro-glycolysis signals. Ongoing experiments in our laboratory will determine whether, in addition to simply more mitochondrial mass, there are qualitative differences between mitochondria in effector $\mathrm{T}$ cells compared with memory $\mathrm{T}$ cells. For example, increased expression of ETC complexes or CPT1a on a per mitochondrion basis could facilitate the 
use of fatty acids for energy via OXPHOS. Given that mitochondria undergo significant changes in $\mathrm{T}$ cells during various phases of the immune response we think that it is very likely that there will also be qualitative differences in these organelles between these cell types.

Our studies revealed that maintaining/increasing mitochondrial mass is critical for $\mathrm{CD}^{+} \mathrm{T}$-cell memory development. Unlike the case for effector $\mathrm{T}$ cells which rely predominantly on glycolytic metabolism, memory $\mathrm{T}$ cells maintain substantial mitochondrial mass, which provides the flexibility to use diverse substrates for energy generation, such as the oxidation of fatty acids. Our earlier microarray analyses comparing 'memory-impaired' TRAF6-deficient $\mathrm{CD}^{+} \mathrm{T}$ cells versus 'memory-competent' control $\mathrm{CD} 8^{+} \mathrm{T}$ cells revealed that in addition to fatty acid oxidation, amino acid catabolism may also be involved in $\mathrm{CD}^{+}{ }^{+} \mathrm{T}$-cell memory development (98). Previous studies have shown that antigenpresenting cells can regulate amino acid availability to $\mathrm{T}$ cells (113-115), which may influence T-cell development during an immune response. Furthermore, autophagy is an important survival pathway when cells are faced with metabolic stress (116). If $\mathrm{T}$ cells experience metabolic stress during an immune response, autophagy could be induced, and this presumably would include the breakdown of amino acids for fuel in addition to lipid oxidation. However, as fats are an efficient energy store, yielding more than twice the energy per gram than either carbohydrate or protein, it is logical that lipids would be the preferential fuel source for long-lived quiescent $\mathrm{T}$ cells. More work will need to be done in the area of substrate utilization in $\mathrm{T}$ cells after infection to reveal whether there is any role for amino acid catabolism fueling the development of memory $\mathrm{T}$ cells.

\section{The question of metabolic conversion, promotion, or maintenance}

It is still unclear whether $\mathrm{T}$ cells that are destined to become memory cells fully commit to using Warburg metabolism in the effector phase and subsequently switch to a quiescent metabolism later, or whether memory cell precursors never fully switch to Warburg metabolism and promote or simply maintain a significant amount of mitochondrial respiratory capacity throughout activation. Although our data as well as those from other laboratories indicate that the population of $\mathrm{CD}^{+}{ }^{+}$effector $\mathrm{T}$ cells generated in vivo or after activation in vitro actively use both glycolysis and OXPHOS $(21,97,104)$, it is not possible to determine whether these measurements are reflecting heterogeneity in the cell populations, where more terminally differentiated effectors T cells are mostly using glycolysis and less differentiated effectors $\mathrm{T}$ cells are using more oxidative metabolism, or whether individual cells actually use both metabolic programs simultaneously. There does seem to be a high degree in uniformity in the effector cell populations generated in vitro, to where activation marker expression and effector function are adopted evenly across the population, which might suggest that metabolic phenotypes are also evenly distributed across the population and that all cells are using both glycolysis and OXPHOS. However, the real answers to these questions will have to wait until it becomes possible to measure metabolism on a single cell level. While it now has been shown that activated $\mathrm{T}$ cells use OXPHOS in addition to glycolysis $(21,97,104)$, it has yet to be determined which one or if both of these energy-generating pathways are actually required for the survival and proliferation of effector $\mathrm{T}$ cells.

Our research has indicated that memory $\mathrm{T}$ cells have more mitochondrial mass than effector $\mathrm{T}$ cells and that IL-15 induces mitochondrial biogenesis (104), suggesting that exposure to IL-15 or perhaps other common- $\gamma$ cytokines, such as IL-7 or IL-4, is critical to ensure that mitochondrial mass is maintained and long-lived memory $\mathrm{T}$ cells can develop/persist (Fig. 3). Whether effector $\mathrm{T}$ cells will receive these cytokine signals can be controlled at many levels, including cytokine and/or cytokine receptor expression, trans-presentation of the cytokine to $\mathrm{T}$ cells by other cells, or T-cell localization to niches where cytokine is expressed $(117,118)$ (Fig. 3). Most likely a combination of all these factors will determine whether a $\mathrm{T}$ cell receives a cytokine signal in vivo. Our unpublished preliminary data indicate that lymph node homing receptors are upregulated quickly after IL-2 withdrawal in vitro, suggesting that once infection-associated signals disappear, $\mathrm{T}$ cells become competent to traffic to the lymph nodes where growth factor cytokines like IL-15 are expressed. A recent study has shown that $\mathrm{CD}^{+}$DCs constitutively express higher levels of IL-15 when compared with other DC subsets (119). In addition to the role of $\mathrm{CD}^{+} \mathrm{DC}$ in cross-priming $\mathrm{CD}^{+} \mathrm{T}$ cells $(120)$, perhaps these cells also support mitochondrial maintenance in $\mathrm{CD}^{+} \mathrm{T}$ cells that are destined to become long-lived memory $\mathrm{T}$ cells via IL15 trans-presentation during priming.

\section{Memory T-cell development in vivo}

The question remains how memory cell formation is organized in vivo. One possibility is that effector $\mathrm{T}$ cells at the lowest end of the growth factor gradient will be the 
first to sense growth factor deprivation and in response will upregulate molecules like CD62L and migrate to the lymph nodes where IL-15 is presented, making these cells more likely to survive contraction. We speculate that the antigen-specific $\mathrm{T}$ cells that continue to rapidly proliferate in response to infection will eventually outpace their mitochondrial biogenesis, resulting in lower mitochondrial mass and respiratory capacity, and thus a higher dependency on glycolysis (Fig. 4). Alternatively, there may be heterogeneity in CD62L expression on antigen-stimulated $\mathrm{T}$ cells already in the early phase of the immune response as a result of variation in strength of $\mathrm{T}$-cell activation. In response to TCR triggering or cytokines, AKT is activated and FOXO transcription factors are sequestered in the cytoplasm (121) (Fig. 3) and thus are unable to drive KLF2 expression (76). In the case of inadequate AKT activity, FOXO transcription factors are not retained in the cytoplasm and can still drive the expression of KLF2 (75) and thereby maintain the expression of several adhesion and chemokine receptors, such as CD62L, CCR7, and $\mathrm{S}_{1} \mathrm{P}_{1}$, which control T-cell migration $(37,74)$. Weak antigen-stimulation results in suboptimal activation of the AKT-mTOR pathway, that is sufficient to drive T-cell growth and proliferation but not to suppress KLF2 expression $(73,76)$. Thus, $\mathrm{T}$ cells that are activated by $\mathrm{a}$ weaker signal will proliferate but also maintain higher expression of CD62L and maintain the ability to migrate to lymph nodes and gain access to growth factor cytokines like IL-15.

Another possibility is that heterogeneity in the effector pool as a result of asymmetric cell division may contribute to the generation of $\mathrm{T}$ cells that are better equipped for memory development than others (122). Asymmetric division could result in unequal distribution of several critical factors, including cytokine receptors, lymph node homing receptors, transcription factors, and mitochondria. Accordingly, it has been shown that cells generated during the peak of infection that have not terminally differentiated, express IL-7R and persist as long-lived memory $\mathrm{T}$ cells (123). It is possible that mitochondria are also unequally distributed during the first divisions after activation, so that terminally differentiated effector $\mathrm{T}$ cells acquire fewer mitochondria, while memory precursor $\mathrm{T}$ cells acquire more.

\section{Bioenergetics and recall responses}

In addition to bioenergetic differences between memory $\mathrm{CD}^{+} \mathrm{T}$ cells and effector $\mathrm{CD}^{+} \mathrm{T}$ cells, we have also shown that naive $\mathrm{CD}^{+} \mathrm{T}$ cells have less $\mathrm{SRC}$ and mitochondrial mass than memory $\mathrm{CD}^{+} \mathrm{T}$ cells $(104)$. We speculate that during an immune response, signals from IL-15, as well as other growth factor cytokines, support mitochondrial biogenesis and thus endow memory cells with greater mitochondrial mass compared with naive $\mathrm{T}$ cells. In addition to the simply enhanced mitochondrial content contributing to bioenergetic differences, qualitative differences in mitochondria may also exist between these cell types, i.e. differences in the expression of ETC complexes or other mitochondrial proteins could result in intrinsic differences in respiratory capacity. Regardless of the variation in the mitochondria between cell types, we suspect that greater mitochondrial mass would indicate that memory $\mathrm{T}$ cells have more readily available ATP-generating capacity than naive $\mathrm{T}$ cells. If this were the case, it may explain why antigen-specific $\mathrm{CD} 8^{+}$ memory $\mathrm{T}$ cells respond faster to re-infection on a per cell basis when compared with their antigen-specific naive $\mathrm{CD}^{+}$ T-cell counterparts. Investigating cell-intrinsic bioenergetics differences between naive and memory $\mathrm{T}$ cells and how this disparity impacts their functionality will be a focus of our future studies.

\section{STAT3}

Two recent studies demonstrated that STAT3 has a critical role in the development and maintenance of memory $\mathrm{T}$ cells $(124,125)$. Siegel et al. (125) showed that patients with dominant-negative STAT3 mutations have a T-cell intrinsic defect resulting in decreased numbers of central memory $\mathrm{T}$ cells. Naive $\mathrm{T}$ cells isolated from these patients and cultured in IL-7 or IL-15 exhibited impaired differentiation into central memory $\mathrm{T}$ cells. The impaired capacity to form central memory $\mathrm{T}$ cells was associated with decreased expression of Bcl6 and SOCS3, two STAT3 responsive transcription factors important in the development of memory $\mathrm{T}$ cells (126-128). Cui et al. (124) demonstrated the intrinsic requirement of STAT3 in $\mathrm{CD}^{+}$ $\mathrm{T}$ cells for memory differentiation and maturation in a mouse model of lymphocytic choriomeningitis virus (LCMV) infection. STAT3-deficient $\mathrm{T}$ cells displayed an effector phenotype, had a shortened lifespan, had reduced self-renewal capacity, and showed poor protective immunity upon secondary infection. In addition, Bcl6 and SOCS3-deficient $\mathrm{CD}^{+} \mathrm{T}$ cells also demonstrated impaired memory T-cell development. Interestingly, it was recently shown that STAT3 is not only present in the cytosol but also in mitochondria, where it regulates the function of 
ETC complexes I and II $(129,130)$. STAT3-deficient cells exhibited defects in ETC function and ATP generation but maintained normal mitochondrial gene expression and content (129). Importantly, it was suggested that STAT3 activity in mitochondria is unrelated to its actions as a transcription factor. Although Cui's study suggests at least a partial role for STAT3-mediated transcriptional effects on memory $\mathrm{T}$-cell formation, it is tempting to speculate that mitochondrial STAT3 plays a role in memory T-cell formation as well. As the importance of fatty acid oxidation and spare respiratory capacity for memory $\mathrm{CD}^{+}$T-cell development has recently become clear, the impaired ETC function and ATP-generating capacity evident in the absence of STAT3 suggests that mitochondrial STAT3 may have a key role in this process. Furthermore, in agreement with the idea that maintaining mitochondrial capacity to utilize fats for energy while not depending solely on glucose and IL-2 is a critical feature for $\mathrm{CD}^{+} \mathrm{T}$ cells to persist as long-lived memory $\mathrm{T}$ cells, it was suggested that the T-cell memory defect in STAT3-deficient patients was potentially resulting from increased reliance on IL-2 (125).

\section{Diet and the immune response}

Malnutrition and immunity

There is abundant epidemiological evidence which suggests that malnutrition impairs vaccine efficacy and increases susceptibility to infections; however, the underlying mechanism is poorly understood $(131,132)$. As the maintenance of long-lived memory $\mathrm{T}$ cells requires homeostatic proliferation and thus availability of building blocks to support the production of new daughter cells, dietary components can be critical to this process. A recent study from Iyer et al. (133) demonstrated that mice that were infected with LCMV on a normal diet but then switched to a low protein diet after memory $\mathrm{T}$ cells were established developed twofold lower numbers of antigen-specific $\mathrm{T}$ cells. Also, acute and basal homeostatic proliferation of $\mathrm{CD} 44^{\text {hi }} \mathrm{CD} 8^{+}$ $\mathrm{T}$ cells was impaired in mice on the low protein diet, which was not due to lower IL-7R or IL-15R expression. In addition, the memory $\mathrm{CD}^{+}{ }^{+} \mathrm{T}$ cells in mice fed the low protein diet showed decreased proliferation upon challenge with LCMV clone 13, resulting in impaired viral clearance. Importantly, supplementation of appropriate protein levels in mice fed the low protein diet rescued the quantitative reduction of memory $\mathrm{CD}^{+} \mathrm{T}$ cells. This study demonstrates the importance of dietary amino acids for optimal maintenance of memory $\mathrm{CD}^{+}{ }^{-} \mathrm{T}$ cells and an adequate secondary effector response.

\section{Caloric restriction and $T$-cell responses}

In contrast with malnutrition, caloric restriction, as defined as a reduction in nutrient availability without malnutrition, has long been known to increase lifespan in a variety of species ranging from yeast to mammals (134). In parallel with the proposed model linking T-cell longevity and maintaining the capacity to use a wide variety of fuels (Fig. 4), the capacity of animals to adapt to metabolic stress or harsh environmental conditions may have evolved along with genetic adaptation for longevity. Indeed, the stress resistance of vertebrate cells in culture positively correlates with the lifespan of the species from which they were isolated (135, 136). Most of the work exploring the molecular pathways that control longevity has been performed using worms, yeast, and fruit flies. Studies have shown that insulin/IGF signaling, DAF-16/FOXO transcription factors, and TOR all play crucial roles in the regulation of metabolism and lifespan (137-142). Inhibition of TOR by the AMPK-FOXO pathway has been shown to positively regulate longevity by caloric restriction in C. elegans (143). In agreement with these findings, administration of rapamycin or metformin, which inhibit mTOR and activate AMPK, respectively, has been demonstrated to increase mammalian lifespan (144, 145), which corresponds with studies showing that these agents increase T-cell lifespan (98, 99, 146). Furthermore, consistent with our studies showing that increased fatty acid metabolism primes $\mathrm{T}$ cells for longevity $(98,104)$, a positive correlation between fat metabolism and increased lifespan has been observed in C. elegans (147).

\section{Mitochondrial function and cellular longevity}

As fatty acid oxidation occurs in the mitochondria, it is logical that maintenance of these organelles is critical for the survival of long-lived memory $\mathrm{T}$ cells (104). Support for this idea comes from studies that compared the transcriptional profiles of the aging process across humans, mice, flies, and worms, and identified the downregulation of nuclear-encoded genes of the mitochondrial ETC as the only age effect common to all four species (148). The decline in mitochondrial function with aging is opposed by caloric restriction by the induction of nuclear encoded genes that promote mitochondrial function (149). A key component in the transcriptional changes upon caloric restriction is increased expression of the transcriptional coactivator PGC- 
$1 \alpha$, a protein that is directly phosphorylated by AMPK (150). Activation of PGC- $1 \alpha$ results in induction of mitochondrial biogenesis, increased mitochondrial respiration and fatty acid oxidation, and regulation of ROS detoxification $(151,152)$. The latter process seems critical to prevent extensive oxidative damage as a result of increased respiration. It is likely that caloric restriction-induced PGC- $1 \alpha$ expression results in a wide array of adaptations to provide a positive setting for increased OXPHOS. For instance, expression of uncoupling proteins, which have been associated with decreased ROS-induced damage, is increased in response to caloric restriction (153). In line with this, the Drosophila homolog of PGC-1 increases mitochondrial gene expression and activity and extends lifespan (154). Future studies are required to determine whether PGC-1 is also the critical regulator in $\mathrm{T}$ cells that links mitochondrial mass to cellular longevity.

It was shown that Tsc1-deficient $\mathrm{T}$ cells (discussed in section on naive $\mathrm{T}$ cells), which have hyperactive mTOR, have a survival defect and fewer mitochondria than cells with functional Tsc1, fitting with their exit from quiescence and decreased longevity and persistence (35). However, it was shown several years ago that mTOR inhibition decreased the gene expression of the mitochondrial transcriptional regulators PGC- $1 \alpha$, ERR- $\alpha$, and nuclear respiratory factors in skeletal muscle, resulting in a decrease in mitochondrial gene expression and oxygen consumption in these cells (155). It is not precisely clear at this time why mTOR signaling induces opposing effects on mitochondrial regulation in these settings, but it may reflect tissue-specific differences or temporal events. Since both mTOR and AMPK have been shown to modulate PGC- $1 \alpha$ activity $(150,155)$, the balance of how these factors regulate mitochondrial changes in $\mathrm{T}$ cells will need to be explored.

\section{Concluding remarks}

In recent years, there has been a renewed focus on immune cell metabolism and the overall importance of particular pathways in defined immunological processes has been established. However, further investigation into when a particular metabolism or bioenergetic process is required for cellular function and survival is still needed, especially concerning how metabolic fluctuations in $\mathrm{T}$ cells play out during immune responses in vivo. In addition, little is known about the relative contribution of metabolic pathways in $\mathrm{T}$ cells to fuel energy production, provide biosynthetic precursors, or generate reducing equivalents to balance the redox status of the cell at a particular time. Defining the metabolic and energetic requirements of $\mathrm{T}$ cells during different phases of an immune response is critical for our understanding of T-cell development and for the future design of therapeutics.

\section{References}

1. Fox CJ, Hammerman PS, Thompson CB. Fuel feeds function: energy metabolism and the T-cell response. Nat Rev Immunol 2005;5:844-852.

2. Jones RG, Thompson CB. Revving the engine: signal transduction fuels $\mathrm{T}$ cell activation. Immunity 2007;27:173-178.

3. Vander Heiden MG, Cantley LC, Thompson CB. Understanding the Warburg effect: the metabolic requirements of cell proliferation. Science 2009;324:1029-1033.

4. Krauss S, Brand MD, Buttgereit F. Signaling takes a breath-new quantitative perspectives on bioenergetics and signal transduction. Immunity 2001;15:497-502.

5. Rathmell JC, VanderHeiden MG, Harris MH, Frauwirth KA, Thompson CB. In the absence of extrinsic signals, nutrient utilization by lymphocytes is insufficient to maintain either cell size or viability. Mol Cell 2000;6:683692.

6. Roos D, Loos JA. Changes in the carbohydrate metabolism of mitogenically stimulated human peripheral lymphocytes. II. Relative importance of glycolysis and oxidative phosphorylation on phytohaemagglutinin stimulation. Exp Cell Res 1973;77:127-135
7. Frauwirth KA, et al. The CD28 signaling pathway regulates glucose metabolism. Immunity 2002; 16:769-777.

8. Wieman HL, Wofford JA, Rathmell JC. Cytokine stimulation promotes glucose uptake via phosphatidylinositol-3 kinase/Akt regulation of Glut 1 activity and trafficking. Mol Biol Cell 2007; 18:1437-1446.

9. Gingras AC, Raught B, Sonenberg N. Regulation of translation initiation by FRAP/mTOR. Genes Dev 2001;15:807-826.

10. Kim DH, et al. mTOR interacts with raptor to form a nutrient-sensitive complex that signals to the cell growth machinery. Cell 2002;110:163-175.

11. -Zoncu R, Efeyan A, Sabatini DM. mTOR: from growth signal integration to cancer, diabetes and ageing. Nat Rev Mol Cell Biol 2011;12:21-35.

12. Barata JT, Silva A, Brandao JG, Nadler LM, Cardoso AA, Boussiotis VA. Activation of PI3K is indispensable for interleukin 7-mediated viability, proliferation, glucose use, and growth of $\mathrm{T}$ cell acute lymphoblastic leukemia cells. J Exp Med 2004;200:659-669.

13. Elstrom RL, et al. Akt stimulates aerobic glycolysis in cancer cells. Cancer Res 2004;64:3892-3899.
14. DeBerardinis RJ, Lum JJ, Hatzivassiliou G, Thompson CB. The biology of cancer: metabolic reprogramming fuels cell growth and proliferation. Cell Metab 2008;7:11-20.

15. Edinger AL, Thompson CB. Akt maintains cell size and survival by increasing mTOR-dependent nutrient uptake. Mol Biol Cell 2002;13:22762288.

16. Rathmell JC, Elstrom RL, Cinalli RM, Thompson CB. Activated Akt promotes increased resting $\mathrm{T}$ cell size, CD28-independent $\mathrm{T}$ cell growth, and development of autoimmunity and lymphoma. Eur J Immunol 2003;33:2223-2232.

17. Warburg O. On respiratory impairment in cancer cells. Science 1956;124:269-270.

18. Jacobs SR, et al. Glucose uptake is limiting in $\mathrm{T}$ cell activation and requires CD28-mediated Aktdependent and independent pathways. J Immunol 2008; 180:4476-4486.

19. Cham CM, Driessens G, O’Keefe JP, Gajewski TF. Glucose deprivation inhibits multiple key gene expression events and effector functions in CD8 + T cells. Eur J Immunol 2008;38:24382450.

20. Carr EL, et al. Glutamine uptake and metabolism are coordinately regulated by ERK/MAPK during 
T lymphocyte activation. J Immunol 2010;185:1037-1044.

21. Wang R, et al. The transcription factor Myc controls metabolic reprogramming upon $\mathrm{T}$ lymphocyte activation. Immunity 2011;35: 871-882.

22. Maciver NJ, Jacobs SR, Wieman HL, Wofford JA, Coloff JL, Rathmell JC. Glucose metabolism in lymphocytes is a regulated process with significant effects on immune cell function and survival. J Leukoc Biol 2008;84:949-957.

23. Greiner EF, Guppy M, Brand K. Glucose is essential for proliferation and the glycolytic enzyme induction that provokes a transition to glycolytic energy production. J Biol Chem 1994;269:31484-31490.

24. Cham CM, Gajewski TF. Glucose availability regulates IFN-gamma production and p70S6 kinase activation in CD8 + effector T cells. J Immunol 2005;174:4670-4677.

25. Newsholme EA, Crabtree B, Ardawi MS Glutamine metabolism in lymphocytes: its biochemical, physiological and clinical importance. Q J Exp Physiol 1985;70:473-489.

26. Newsholme EA, Crabtree B, Ardawi MS. The role of high rates of glycolysis and glutamine utilization in rapidly dividing cells. Biosci Rep 1985;5:393-400.

27. Wellen KE, et al. The hexosamine biosynthetic pathway couples growth factor-induced glutamine uptake to glucose metabolism. Genes Dev 2010;24:2784-2799.

28. Wellen KE, Thompson CB. Cellular metabolic stress: considering how cells respond to nutrient excess. Mol Cell 2010;40:323-332.

29. Deberardinis RJ, Sayed N, Ditsworth D, Thompson CB. Brick by brick: metabolism and tumor cell growth. Curr Opin Genet Dev 2008; 18:54-61.

30. Newsholme P, Curi R, Pithon Curi TC, Murphy CJ, Garcia C, Pires de Melo M. Glutamine metabolism by lymphocytes, macrophages, and neutrophils: its importance in health and disease. J Nutr Biochem 1999;10:316-324.

31. DeBerardinis RJ, et al. Beyond aerobic glycolysis: transformed cells can engage in glutamine metabolism that exceeds the requirement for protein and nucleotide synthesis. Proc Natl Acad Sci USA 2007;104:19345-19350.

32. Metallo CM, et al. Reductive glutamine metabolism by IDH1 mediates lipogenesis under hypoxia. Nature 2012;481:380-384.

33. Eagle H, Oyama VI, Levy M, Horton CL, Fleischman R. The growth response of mammalian cells in tissue culture to L-glutamine and L-glutamic acid. J Biol Chem 1956;218: 607-616.

34. Yusuf I, Fruman DA. Regulation of quiescence in lymphocytes. Trends Immunol 2003;24: 380-386.

35. Yang K, Neale G, Green DR, He W, Chi H. The tumor suppressor Tsc1 enforces quiescence of naive $\mathrm{T}$ cells to promote immune homeostasis and function. Nat Immunol 2011;12:888-897.

36. O’Brien TF, et al. Regulation of T-cell survival and mitochondrial homeostasis by TSC1. Eur J Immunol 2011;41:3361-3370.
37. Carlson CM, et al. Kruppel-like factor 2 regulates thymocyte and T-cell migration. Nature 2006;442:299-302.

38. Kerdiles YM, et al. Foxo1 links homing and survival of naive $\mathrm{T}$ cells by regulating L-selectin, CCR7 and interleukin 7 receptor. Nat Immunol 2009; 10:176-184.

39. Kerdiles YM, et al. Foxo transcription factors control regulatory $\mathrm{T}$ cell development and function. Immunity 2010;33:890-904

40. Takada K, et al. Kruppel-like factor 2 is required for trafficking but not quiescence in postactivated T cells. J Immunol 2011;186:775-783.

41. Yamada T, Park CS, Mamonkin M, Lacorazza HD. Transcription factor ELF4 controls the proliferation and homing of $\mathrm{CD} 8+\mathrm{T}$ cells via the Kruppel-like factors KLF4 and KLF2. Nat Immunol 2009;10:618-626.

42. Yamada T, Gierach K, Lee PH, Wang X, Lacorazza HD. Cutting edge: expression of the transcription factor E74-like factor 4 is regulated by the mammalian target of rapamycin pathway in CD8 + T cells. J Immunol 2010;185:38243828.

43. Schluns KS, Kieper WC, Jameson SC, Lefrancois L. Interleukin-7 mediates the homeostasis of naive and memory CD8 $\mathrm{T}$ cells in vivo. Nat Immunol 2000;1:426-432.

44. Tan JT, et al. IL-7 is critical for homeostatic proliferation and survival of naive T cells. Proc Natl Acad Sci USA 2001;98:8732-8737.

45. Rao RR, Li Q, Bupp MR, Shrikant PA. Transcription factor Foxol represses T-bet-mediated effector functions and promotes memory CD8(+) T cell differentiation. Immunity 2012;36:374-387.

46. Furuyama T, Kitayama K, Yamashita H, Mori N Forkhead transcription factor FOXO1 (FKHR) dependent induction of PDK4 gene expression in skeletal muscle during energy deprivation. Biochem J 2003;375:365-371.

47. Nahle Z, et al. CD36-dependent regulation of muscle FoxO1 and PDK4 in the PPAR delta/betamediated adaptation to metabolic stress. J Biol Chem 2008;283:14317-14326.

48. Feng X, Wang H, Takata H, Day TJ, Willen J, Hu H. Transcription factor Foxp1 exerts essential cell-intrinsic regulation of the quiescence of naive T cells. Nat Immunol 2011;12:544-550.

49. Surh CD, Sprent J. Homeostasis of naive and memory T cells. Immunity 2008;29:848-862.

50. Lehtinen MK, et al. A conserved MST-FOXO signaling pathway mediates oxidative-stress responses and extends life span. Cell 2006;125:987-1001.

51. Nehme NT, et al. MST1 mutations in autosomal recessive primary immunodeficiency characterized by defective naive $\mathrm{T}$ cells survival Blood 2012;119:3458-3468.

52. Wu Q, et al. The tuberous sclerosis complexmammalian target of rapamycin pathway maintains the quiescence and survival of naive $\mathrm{T}$ cells. J Immunol 2011;187:1106-1112.

53. Zhang L, et al. TSC1/2 signaling complex is essential for peripheral naive CD8 T cell survival and homeostasis in mice. PLoS ONE 2012;7: e30592.
54. Chen C, et al. TSC-mTOR maintains quiescence and function of hematopoietic stem cells by repressing mitochondrial biogenesis and reactive oxygen species. J Exp Med 2008;205:23972408

55. Alessi DR, Sakamoto K, Bayascas JR. LKB1dependent signaling pathways. Annu Rev Biochem 2006;75:137-163.

56. Lee JH, et al. Energy-dependent regulation of cell structure by AMP-activated protein kinase. Nature 2007;447:1017-1020.

57. Hemminki A, et al. A serine/threonine kinase gene defective in Peutz-Jeghers syndrome. Nature 1998;391:184-187.

58. Gan B, et al. Lkb1 regulates quiescence and metabolic homeostasis of haematopoietic stem cells. Nature 2010;468:701-704.

59. Gurumurthy S, et al. The Lkb1 metabolic sensor maintains haematopoietic stem cell survival. Nature 2010;468:659-663.

60. Nakada D, Saunders TL, Morrison SJ. Lkb1 regulates cell cycle and energy metabolism in haematopoietic stem cells. Nature 2010;468:653-658.

61. Shaw RJ, et al. The tumor suppressor LKB1 kinase directly activates AMP-activated kinase and regulates apoptosis in response to energy stress. Proc Natl Acad Sci USA 2004;101:3329-3335.

62. Woods A, et al. LKB1 is the upstream kinase in the AMP-activated protein kinase cascade. Curr Biol 2003;13:2004-2008.

63. Wong AK, Howie J, Petrie JR, Lang CC. AMPactivated protein kinase pathway: a potential therapeutic target in cardiometabolic disease. Clin Sci 2009; 116:607-620

64. Brown NF, Stefanovic-Racic M, Sipula IJ, Perdomo G. The mammalian target of rapamycin regulates lipid metabolism in primary cultures of rat hepatocytes. Metabolism 2007;56:15001507

65. Sipula IJ, Brown NF, Perdomo G. Rapamycinmediated inhibition of mammalian target of rapamycin in skeletal muscle cells reduces glucose utilization and increases fatty acid oxidation. Metabolism 2006;55:1637-1644.

66. Shaw RJ, et al. The LKB1 tumor suppressor negatively regulates mTOR signaling. Cancer Cell 2004;6:91-99.

67. Ha J, Daniel S, Broyles SS, Kim KH. Critical phosphorylation sites for acetyl-CoA carboxylase activity. J Biol Chem 1994;269:22162-22168.

68. Kerner J, Hoppel C. Fatty acid import into mitochondria. Biochim Biophys Acta 2000; 1486: 1-17.

69. Cao Y, Li H, Liu H, Zheng C, Ji H, Liu X. The serine/threonine kinase LKB1 controls thymocyte survival through regulation of AMPK activation and Bcl-XL expression. CellRes 2010;20:99-108.

70. Tamas $P$, et al. LKB1 is essential for the proliferation of T-cell progenitors and mature peripheral T cells. Eur J Immunol 2010;40:242253.

71. MacIver NJ, et al. The liver kinase B1 is a central regulator of $\mathrm{T}$ cell development, activation, and metabolism. J Immunol 2011;187:4187-4198.

72. Hand TW, et al. Differential effects of STAT5 and PI3K/AKT signaling on effector and memory 
CD8 T-cell survival. Proc Natl Acad Sci USA 2010;107:16601-16606.

73. Cornish GH, Sinclair LV, Cantrell DA. Differential regulation of T-cell growth by $\mathrm{IL}-2$ and IL-15. Blood 2006;108:600-608.

74. Sinclair LV, et al. Phosphatidylinositol-3-OH kinase and nutrient-sensing mTOR pathways control T lymphocyte trafficking. Nat Immunol 2008;9:513-521.

75. Waugh C, Sinclair L, Finlay D, Bayascas JR, Cantrell D. Phosphoinositide $(3,4,5)$-triphosphate binding to phosphoinositide-dependent kinase 1 regulates a protein kinase $\mathrm{B} / \mathrm{Akt}$ signaling threshold that dictates T-cell migration, not proliferation. Mol Cell Biol 2009;29:5952-5962.

76. Finlay D, Cantrell DA. Metabolism, migration and memory in cytotoxic T cells. Nat Rev Immunol 2011;11:109-117.

77. Macintyre AN, et al. Protein kinase B controls transcriptional programs that direct cytotoxic $\mathrm{T}$ cell fate but is dispensable for $\mathrm{T}$ cell metabolism. Immunity 2011;34:224-236.

78. Michalek RD, et al. Cutting edge: distinct glycolytic and lipid oxidative metabolic programs are essential for effector and regulatory CD4 $+\mathrm{T}$ cell subsets. J Immunol 2011;186:3299-3303.

79. Shi LZ, et al. HIF1alpha-dependent glycolytic pathway orchestrates a metabolic checkpoint for the differentiation of TH17 and Treg cells. J Exp Med 2011;208:1367-1376.

80. Nizet V, Johnson RS. Interdependence of hypoxic and innate immune responses. Nat Rev Immunol 2009;9:609-617.

81. Papandreou I, Cairns RA, Fontana L, Lim AL, Denko NC. HIF-1 mediates adaptation to hypoxia by actively downregulating mitochondrial oxygen consumption. Cell Metab 2006;3: 187-197.

82. Schaffer JE. Lipotoxicity: when tissues overeat. Curr Opin Lipidol 2003;14:281-287.

83. Dang CV, Semenza GL. Oncogenic alterations of metabolism. Trends Biochem Sci 1999;24:68-72.

84. Gordan JD, Thompson CB, Simon MC. HIF and c-Myc: sibling rivals for control of cancer cell metabolism and proliferation. Cancer Cell 2007;12:108-113.

85. Li F, et al. Myc stimulates nuclearly encoded mitochondrial genes and mitochondrial biogenesis. Mol Cell Biol 2005;25:6225-6234

86. Zhang $\mathrm{H}$, et al. HIF-1 inhibits mitochondrial biogenesis and cellular respiration in VHL deficient renal cell carcinoma by repression of CMYC activity. Cancer Cell 2007;11:407-420

87. Powell JD, Pollizzi KN, Heikamp EB, Horton MR. Regulation of immune responses by mTOR. Annu Rev Immunol 2012;30:39-68.

88. Laplante M, Sabatini DM. mTOR signaling at a glance. JJ Cell Sci 2009;122:3589-3594

89. Delgoffe GM, et al. The mTOR kinase differentially regulates effector and regulatory $\mathrm{T}$ cell lineage commitment. Immunity 2009;30:832-844

90. Delgoffe GM, et al. The kinase mTOR regulates the differentiation of helper $\mathrm{T}$ cells through the selective activation of signaling by mTORC1 and mTORC2. Nat Immunol 2011; 12:295-303.
91. Giguere V. Transcriptional control of energy homeostasis by the estrogen-related receptors. Endocr Rev 2008;29:677-696.

92. Villena JA, Kralli A. ERRalpha: a metabolic function for the oldest orphan. Trends Endocrinol Metab 2008;19:269-276.

93. Michalek RD, et al. Estrogen-related receptoralpha is a metabolic regulator of effector T-cell activation and differentiation. Proc Natl Acad Sci USA 2011;108:18348-18353.

94. Tennessen JM, Baker KD, Lam G, Evans J, Thummel CS. The Drosophila estrogen-related receptor directs a metabolic switch that supports developmental growth. Cell Metab 2011;13: 139-148.

95. D’Souza AD, Parikh N, Kaech SM, Shadel GS. Convergence of multiple signaling pathways is required to coordinately up-regulate $\mathrm{mtDNA}$ and mitochondrial biogenesis during $\mathrm{T}$ cell activation. Mitochondrion 2007;7:374-385.

96. Ao A, Wang H, Kamarajugadda S, Lu J. Involvement of estrogen-related receptors in transcriptional response to hypoxia and growth of solid tumors. Proc Natl Acad Sci USA 2008; 105:7821-7826.

97. Gatza E, et al. Manipulating the bioenergetics of alloreactive $\mathrm{T}$ cells causes their selective apoptosis and arrests graft-versus-host disease. Sci Trans Med 2011;3:67ra68.

98. Pearce EL, et al. Enhancing CD8 T-cell memory by modulating fatty acid metabolism. Nature 2009;460:103-107.

99. Araki K, et al. mTOR regulates memory CD8 Tcell differentiation. Nature 2009;460:108-112.

100. Rao RR, Li Q, Odunsi K, Shrikant PA. The mTOR kinase determines effector versus memory $\mathrm{CD} 8+\mathrm{T}$ cell fate by regulating the expression of transcription factors T-bet and eomesodermin. Immunity 2010;32:67-78.

101. Intlekofer AM, et al. Effector and memory CD8 + T cell fate coupled by T-bet and eomesodermin. Nat Immunol 2005;6:12361244.

102. Joshi NS, et al. Inflammation directs memory precursor and short-lived effector $\mathrm{CD} 8(+) \mathrm{T}$ cell fates via the graded expression of T-bet transcription factor. Immunity 2007;27:281-295.

103. Banerjee $\mathrm{A}$, et al. Cutting edge: the transcription factor eomesodermin enables CD8 $+\mathrm{T}$ cells to compete for the memory cell niche. J Immunol 2010;185:4988-4992.

104. van derWindt GJ, et al. Mitochondrial respiratory capacity is a critical regulator of $\mathrm{CD} 8(+) \mathrm{T}$ cell memory development. Immunity 2012;36: 68-78.

105. Choi SW, Gerencser AA, Nicholls DG. Bioenergetic analysis of isolated cerebrocortical nerve terminals on a microgram scale: spare respiratory capacity and stochastic mitochondrial failure. J Neurochem 2009;109:1179-1191.

106. Nicholls DG. Spare respiratory capacity, oxidative stress and excitotoxicity. Biochem Soc Trans 2009;37:1385-1388.

107. Nicholls DG, Darley-Usmar VM, Wu M, Jensen PB, Rogers GW, Ferrick DA. Bioenergetic profile experiment using $\mathrm{C} 2 \mathrm{C} 12$ myoblast cells. J Vis Exp 2010;46:2511.
108. Yadava N, Nicholls DG. Spare respiratory capacity rather than oxidative stress regulates glutamate excitotoxicity after partial respiratory inhibition of mitochondrial complex I with rotenone. J Neurosci 2007;27:7310-7317.

109. Ferrick DA, Neilson A, Beeson C. Advances in measuring cellular bioenergetics using extracellular flux. Drug Discov Today 2008; 13:268-274.

110. Zaugg K, et al. Carnitine palmitoyltransferase 1C promotes cell survival and tumor growth under conditions of metabolic stress. Genes Dev 2011;25:1041-1051

111. Ramsay RR, Zammit VA. Carnitine acyltransferases and their influence on CoA pools in health and disease. Mol Aspects Med 2004;25:475-493.

112. Deberardinis RJ, Lum JJ, Thompson CB. Phosphatidylinositol 3-kinase-dependent modulation of carnitine palmitoyltransferase $1 \mathrm{~A}$ expression regulates lipid metabolism during hematopoietic cell growth. J Biol Chem 2006;281:37372-37380.

113. Angelini G, et al. Antigen-presenting dendritic cells provide the reducing extracellular microenvironment required for T lymphocyte activation. Proc Natl Acad Sci USA 2002;99:1491-1496.

114. Edinger AL, Thompson CB. Antigen-presenting cells control $\mathrm{T}$ cell proliferation by regulating amino acid availability. Proc Natl Acad Sci USA 2002;99:1107-1109

115. Mellor AL, Munn DH. IDO expression by dendritic cells: tolerance and tryptophan catabolism. Nat Rev Immunol 2004;4:762774.

116. Lum JJ, et al. Growth factor regulation of autophagy and cell survival in the absence of apoptosis. Cell 2005;120:237-248.

117. McGill J, Van Rooijen N, Legge KL. IL-15 transpresentation by pulmonary dendritic cells promotes effector CD8 $\mathrm{T}$ cell survival during influenza virus infection. J Exp Med 2010;207:521-534.

118. Stonier SW, Ma LJ, Castillo EF, Schluns KS. Dendritic cells drive memory CD8 T-cell homeostasis via IL-15 transpresentation. Blood 2008; 112:4546-4554.

119. Colpitts SL, Stoklasek TA, Plumlee CR, Obar JJ, Guo C, Lefrancois L. Cutting edge: the role of IFN-alpha receptor and MyD88 signaling in induction of IL-15 expression in vivo. J Immunol 2012;188:2483-2487.

120. Hildner K, et al. Batf3 deficiency reveals a critical role for CD8alpha+ dendritic cells in cytotoxic $\mathrm{T}$ cell immunity. Science 2008;322:1097-1100.

121. Fabre S, et al. Stable activation of phosphatidylinositol 3-kinase in the T cell immunological synapse stimulates Akt signaling to FoxO1 nuclear exclusion and cell growth control. J Immunol 2005; 174:4161-4171.

122. Chang JT, et al. Asymmetric T lymphocyte division in the initiation of adaptive immune responses. Science 2007;315:1687-1691.

123. Kaech SM, Tan JT, Wherry EJ, Konieczny BT, Surh CD, Ahmed R. Selective expression of the interleukin 7 receptor identifies effector CD8 T 
cells that give rise to long-lived memory cells. Nat Immunol 2003;4:1191-1198.

124. Cui W, Liu Y, Weinstein JS, Craft J, Kaech SM. An interleukin-21-interleukin-10-STAT3 pathway is critical for functional maturation of memory CD8 + T cells. Immunity 2011;35:792-805.

125. Siegel AM, et al. A critical role for STAT3 transcription factor signaling in the development and maintenance of human $\mathrm{T}$ cell memory. Immunity 2011;35:806-818.

126. Ichii $\mathrm{H}$, et al. Role for Bcl-6 in the generation and maintenance of memory CD8 $+\mathrm{T}$ cells. Nat Immunol 2002;3:558-563.

127. Ichii H, Sakamoto A, Kuroda Y, Tokuhisa T. Bcl6 acts as an amplifier for the generation and proliferative capacity of central memory CD8 + T cells. J Immunol 2004;173:883-891.

128. Pellegrini M, et al. IL-7 engages multiple mechanisms to overcome chronic viral infection and limit organ pathology. Cell 2011;144: 601-613.

129. Wegrzyn J, et al. Function of mitochondrial Stat3 in cellular respiration. Science 2009;323:793-797.

130. Gough DJ, Corlett A, Schlessinger K, Wegrzyn J, Larner AC, Levy DE. Mitochondrial STAT3 supports Ras-dependent oncogenic transformation. Science 2009;324:1713-1716.

131. Savy M, et al. Landscape analysis of interactions between nutrition and vaccine responses in children. J Nutr 2009;139:2154S2218S.

132. Scrimshaw NS, SanGiovanni JP. Synergism of nutrition, infection, and immunity: an overview. Am J Clin Nutr 1997;66:464S-477S.

133. Iyer SS, et al. Protein energy malnutrition impairs homeostatic proliferation of memory CD8 T cells. J Immunol 2012;188:77-84.

134. Stanfel MN, Shamieh LS, Kaeberlein M, Kennedy BK. The TOR pathway comes of age. Biochim Biophys Acta 2009;1790:1067-1074.

135. Kapahi P, Boulton ME, Kirkwood TB. Positive correlation between mammalian life span and cellular resistance to stress. Free Radic Biol Med 1999;26:495-500.

136. Kenyon C. The plasticity of aging: insights from long-lived mutants. Cell 2005;120:449-460.

137. Kapahi P, Zid BM, Harper T, Koslover D, Sapin V, Benzer S. Regulation of lifespan in Drosophila by modulation of genes in the TOR signaling pathway. Curr Biol 2004;14:885-890.

138. Kapahi P, Zid B. TOR pathway: linking nutrient sensing to life span. Sci Aging Knowledge Environ 2004;2004:PE34.

139. Ogg S, Ruvkun G. The C. elegans PTEN homolog, DAF-18, acts in the insulin receptorlike metabolic signaling pathway. Mol Cell 1998;2:887-893.

140. Kenyon C, Chang J, Gensch E, Rudner A, Tabtiang R. A C. elegans mutant that lives twice as long as wild type. Nature 1993;366:461-464.

141. Lin K, Dorman JB, Rodan A, Kenyon C. daf-16: An HNF-3/forkhead family member that can function to double the life-span of Caenorhabditis elegans. Science 1997;278:1319-1322.

142. Kaeberlein M, et al. Regulation of yeast replicative life span by TOR and Sch9 in response to nutrients. Science 2005; 310:1193-1196.

143. Greer EL, Banko MR, Brunet A. AMP-activated protein kinase and FoxO transcription factors in dietary restriction-induced longevity. Ann NY Acad Sci 2009;1170:688-692.

144. Anisimov VN, Semenchenko AV, Yashin AI. Insulin and longevity: antidiabetic biguanides as geroprotectors. Biogerontology 2003;4: 297-307.

145. Harrison DE, et al. Rapamycin fed late in life extends lifespan in genetically heterogeneous mice. Nature 2009;460:392-395.

146. Pearce EL. Metabolism in T cell activation and differentiation. Curr Opin Immunol 2010;22:314-320.
147. Wang MC, O’Rourke EJ, Ruvkun G. Fat metabolism links germline stem cells and longevity in C. elegans. Science 2008;322:957-960.

148. Zahn JM, et al. AGEMAP: a gene expression database for aging in mice. PLoS Genet 2007;3: e201.

149. Anderson RM, et al. Dynamic regulation of PGC-1alpha localization and turnover implicates mitochondrial adaptation in calorie restriction and the stress response. Aging Cell 2008;7: 101-111.

150. Jager S, Handschin C, St-Pierre J, Spiegelman BM. AMP-activated protein kinase (AMPK) action in skeletal muscle via direct phosphorylation of PGC-1alpha. Proc Natl Acad Sci USA 2007;104:12017-12022.

151. Finley LW, et al. Skeletal muscle transcriptional coactivator PGC-1alpha mediates mitochondrial, but not metabolic, changes during calorie restriction. Proc Natl Acad Sci USA 2012;109:2931-2936.

152. Scarpulla RC. Metabolic control of mitochondrial biogenesis through the PGC-1 family regulatory network. Biochim Biophys Acta 2011;1813:1269-1278.

153. Asami DK, et al. Effect of aging, caloric restriction, and uncoupling protein 3 (UCP3) on mitochondrial proton leak in mice. Exp Gerontol 2008;43:1069-1076.

154. Rera M, et al. Modulation of longevity and tissue homeostasis by the Drosophila PGC-1 homolog. Cell Metab 2011;14:623-634.

155. Cunningham JT, Rodgers JT, Arlow DH, Vazquez F, Mootha VK, Puigserver P. mTOR controls mitochondrial oxidative function through a YY1PGC-1 alpha transcriptional complex. Nature 2007; 450:736-740. 